\title{
A New Construction of 2-Alkoxypyrans by an Acylation-Reductive Cyclization Sequence
}

\author{
Lars V. Heumann and Gary E. Keck \\ Department of Chemistry, University of Utah, 315 South 1400 East RM 2020, Salt Lake City, Utah, \\ $84112-0850$
}

\section{Abstract}

new convergent synthetic approach to a pyran motif common to many naturally occurring structures is described. In this approach, two fragments are joined by esterification, and a subsequent intramolecular reductive cyclization affords the 2-hydroxypyran.

Certain structural elements are often found as recurring themes in a variety of natural products. One such motif is represented by substituted 2-hydroxypyrans, which are found in a large number of biologically relevant molecules. Two examples of recent interest would include bryostatin $1(\mathbf{1})^{1,2,3}$ and acutiphycin (2) (Figure 1). ${ }^{4}$

Of the methods available to access such pyrans, two are most commonly employed (Scheme 1). The first of these begins with the synthesis of a lactone which is then subjected to a nucleophilic addition reaction with a carbanion. ${ }^{5}$ The second, and most common, method exploits the ease of cyclization of 1,5-hydroxyketones. ${ }^{3 \mathrm{e}, \mathrm{g}, \mathrm{h}}$ Both techniques have successfully been utilized in natural product synthesis, their execution, nonetheless, has to be carefully synchronized with the overall synthetic strategy. In most cases, hydroxypyran structures are "stored" as mixed ketals (2-methoxypyrans) during other synthetic steps.

Because of our interest in such structures, we have been led to investigate a new procedure that addresses the asymmetric synthesis of these pyrans by an inherently convergent strategy (Scheme 2). In this approach, we chose an initial disconnection of the desired 2-hydroxypyran 3 between $\mathrm{C}_{2}$ and $\mathrm{C}_{3}$. This somewhat unusual disconnection gives rise to an ester intermediate 5 which can be obtained by acylation of alcohol 7 with an acid 6 . This approach offers the advantage of making the subsequent $\mathrm{C}-\mathrm{C}$ coupling reaction intramolecular. The alcohol 7 can in principle be prepared in a number of ways, but the preparation of this intermediate by the reaction of aldehyde $\mathbf{8}$ with allylstannane $\mathbf{9}$ is particularly direct.

Thus the initial reaction in this sequence takes advantage of an earlier development from our laboratory. Addition of tributyl-(2-chloromethyl)allylstannane $\mathbf{9}$ to aldehydes $\mathbf{8}$ using the $\mathrm{BINOL} / \mathrm{Ti}(\mathrm{O} i \mathrm{Pr})_{4}(\mathrm{BITIP})$ catalytic asymmetric allylation (CAA) protocol has previously been shown to produce homoallylic alcohols 7 in high yield and with excellent enantioselectivity.

$3 \mathrm{e}$ It was our intent to now utilize the allylic chloride as a precursor to a carbanion intermediate $\mathbf{4}$, after acylation of the homoallylic alcohol moiety in $\mathbf{7}$.

As a starting point of our investigation, the homoallylic alcohol, prepared via CAA reaction between stannane 9 and hydrocinnamaldehyde, was acylated with propionyl chloride to provide ester 10 (Table 1). Initial attempts to effect the desired reductive cyclization reaction 
using magnesium as the reductant resulted in low yields of the cyclization product along with considerable amounts of recovered starting material. Attempts to improve the yield by replacing magnesium with $\mathrm{SmI}_{2}$ (either alone or in the presence of catalytic amounts of $\mathrm{NiI}_{2}$ and HMPA as additives) were not successful. 6,7

The detection of some pyran product together with the isolation of unreacted starting material, however, led us to examine the use of the corresponding iodide $\mathbf{1 1}$ in this reaction. Using magnesium as the reducing agent, the pyran was obtained in higher yield, but as before the reaction was incomplete. ${ }^{8}$ Use of indium resulted in the formation of a complex reaction mixture. Metal halogen exchange using tert-butyllithium also afforded some of the pyran. However, $\mathrm{SmI}_{2}$ was found to be the reagent of choice, as this provided pyran $\mathbf{1 2}$ from iodide $\mathbf{1 1}$ in near quantitative yield.

The initial work on substrates $\mathbf{1 0}$ and $\mathbf{1 1}$ also allowed us to obtain some information about the properties of these pyrans. After the cyclization of iodide 11, the 2-hydroxypyran was isolated after chromatography on silica gel but with a considerable loss of material. However, workup and subsequent methanolysis of the initial cyclization product prior to purification by chromatography afforded the corresponding 2-methoxypyran 12 in excellent yield. Hence, the 2-methoxypyrans became our derivative of choice for product isolation and purification. Interestingly, simple addition of an excess of methanol or trimethyl orthoformate to the reaction mixture after the $\mathrm{SmI}_{2}$ mediated cyclization was complete did not afford any of the desired 2methoxypyran; addition of CSA to this mixture also did not have any observable effect.

Table 2 summarizes the assembly of several representative 2-methoxypyrans using this sequence. The initial CAA proceeded in high yield and with excellent $e r$ in all cases examined. The cyclization precursors were then obtained from the chiral alcohols through a simple esterification. The iodides proved accessible in essentially quantitative yield through a Finkelstein reaction. The details of these reactions for each case are provided in the supplementary material. It is worthy of note that the allylic iodides proved to be surprisingly stable. Generally, the pyran products were also stable and could be stored at $-20{ }^{\circ} \mathrm{C}$ neat or in solution without noticeable decomposition for several months. However, we also found that some batches of $\mathrm{CDCl}_{3}$ used as an NMR solvent led to decomposition of the 2-methoxypyrans. Therefore, $\mathrm{CDCl}_{3}$ was filtered through a small plug of alumina prior to use.

As can be seen from Table 2 the cyclization yields are uniformly high, near quantitative in most cases. Aliphatic as well as aromatic substituents are tolerated for the alcohol segment $\left(\mathrm{R}_{1}\right)$. This is also the case for the carbonyl portion $\left(\mathrm{R}_{2}\right)$. In addition, the cyclization proceeded without elimination for substrates with benzyl ethers $\beta$ to the carbonyl (Table 2, Entries 3 and 8 ) and without epimerization for a substrate with an $\alpha$-stereocenter (Table 2, Entry 2). The sterically demanding $t$-butyl substituent did not interfere with the addition into the ester carbonyl during the cyclization (Table 2, Entry 4). Although a significant drop in yield was observed for an $\alpha \beta$-unsaturated ester substrate, it is not clear whether the cyclization or methanolysis step was compromised (Table 2, Entry 6). Nonetheless, the yield in this case was still preparatively useful.

The formation of the $\alpha$-isomer (axial methyl ether) is generally preferred during the methanolysis. In some cases both isomers were obtained and the product was isolated as a mixture. The 2-methoxypyrans in entries 5 and 9 represent exceptions (Table 2): while both anomers were formed, the $\mathrm{R}_{f}$ values were sufficiently different to allow for the isolation and identification of the individual diastereomers.

To put our approach to these functionalized pyrans into perspective with respect to possible applications, we decided to investigate these conditions in the context of our ongoing bryostatin 
analogue studies 9 and also to investigate the application of this methodology in the construction of a macrocycle with an embedded pyran.

A simplified version of the bryostatin $\mathrm{AB}$ ring system was accessed by using a combination of the pyran annulation protocol developed earlier in our laboratory $9 \mathrm{c}$ in tandem with the procedure described in this manuscript (Scheme 3). Thus, pyran $\mathbf{1 6}$ was synthesized in two steps starting with a CAA between aldehyde 13 and reagent 14 which was followed by an annulation with aldehyde 15. ${ }^{9 \mathrm{c}}$ Deprotection of the silyl ether and a two step oxidation sequence provided acid 17. ${ }^{9 \mathrm{~b}, \mathrm{c}}$ Alcohol 18 was obtained as described above through a CAA reaction between aldehyde $\mathbf{1 5}$ and the chloromethylallylstannane reagent $\mathbf{9}$. An esterification between acid $\mathbf{1 7}$ and alcohol $\mathbf{1 8}$ using EDCI provided the substrate for reductive cyclization, ester 19. Following the new protocol, the chloride was exchanged for an iodide using $\mathrm{NaI}$ in acetone. Reductive cyclization of the iodide by reaction with $\mathrm{SmI}_{2}$ in $\mathrm{THF}$ at $0{ }^{\circ} \mathrm{C}$ followed by methanolysis provided the bryostatin $\mathrm{AB}$ ring segment analogue $\mathbf{2 0}$ as a single diastereomer, in $91 \%$ isolated yield from chloroester 19.

An example of this $\mathrm{SmI}_{2}$ mediated cyclization in the context of a macrocycle is provided below (Scheme 4). Aldehyde 21 was accessed from $\omega$-hydroxy hexadecanoic acid in two steps. ${ }^{10}$

Addition of reagent 9 under BITIP catalysis and subsequent silylation of the alcohol afforded compound 22. Hydrolysis of the thiol ester ${ }^{11}$ and desilylation ${ }^{12}$ gave the seco-acid which was transformed into macrocycle $\mathbf{2 3}$ in excellent yield following a carefully modified Yamaguchi procedure. ${ }^{13,14}$ Following the standard protocol, the chloride was exchanged for an iodide using $\mathrm{NaI}$ in acetone. Treatment of the intermediate iodide with $\mathrm{SmI}_{2}$ followed by methanolysis provided the bicyclic compound $\mathbf{2 4}$, again as a single isomer. It should be noted that, contrary to what might have been anticipated in this reaction sequence, the allylic chloride survives a number of conditions and procedures without incident.

In summary we have developed a versatile new method for the convergent assembly of chiral 2-methoxypyrans. This methodology offers an attractive alternative strategy to those presently available. In this context, it should be noted that, of the two bond-forming reactions required, fragment assembly is achieved by bimolecular esterification (C-O bond formation), while the reductive $\mathrm{C}-\mathrm{C}$ bond forming event is intramolecular. This is an important strategic advantage, as methodologies for bimolecular esterification reactions are well developed and highly reliable. The subsequent intramolecular reductive cyclization reaction has been shown (this work) to also be quite reliable and high yielding. Use of the allylic iodide incorporates a malleable and flexible functional group in the product where required for structures of polyacetate or propionate origin, such as those in $\mathbf{1}$ and $\mathbf{2}$. Thus the overall approach provides an expeditious assembly of such pyrans.

\section{Supplementary Material}

Refer to Web version on PubMed Central for supplementary material.

\section{References}

(1). For a recent review see: Hale KJ, Hummersone MG, Manaviazar S, Frigerio M. Nat. Prod. Rep 2002;19:413. [PubMed: 12195811]

(2)(a). Ohmori K, Ogawa Y, Obitsu T, Ishikawa Y, Nishiyama S, Yamamura S. Angew. Chem., Int. Ed. Engl 2000;39:2290. [PubMed: 10941067] (b) Evans DA, Carter PH, Charette AB, Prunet JA, Lautens M. J. Am. Chem. Soc 1999;121:7540. (c) Kageyama M, Tamura T, Nantz MH, Roberts JC, Somfai P, Whritenour DC, Masamune S. J. Am. Chem. Soc 1990;112:7407.

(3)(a). For additional recent synthetic work in this area, see: Trost BM, Yang H, Thiel OR, Frontier AJ, Brindle CS. J. Am. Chem. Soc 2007;129:2206. [PubMed: 17279751] (b) Keck GE, Welch DS, Poudel YB. Tetrahedron Lett 2006;47:8267. [PubMed: 17404602] (c) Keck GE, Welch DS, Vivian 
PK. Org. Lett 2006;8:3667. [PubMed: 16898787] (d) Ball M, Bradshaw BJ, Dumeunier R, Gregson TJ, MacCormick S, Omori H, Thomas EJ. Tetrahedron Lett 2006;47:2223. (e) Keck GE, Yu T, McLaws MD. J. Org. Chem 2005;70:2543. [PubMed: 15787541] (f) Voight EA, Seradj H, Roethle PA, Burke SD. Org. Lett 2004;6:4045. [PubMed: 15496095] (g) Voight EA, Roethle PA, Burke SD. J. Org. Chem 2004;69:4534. [PubMed: 15202915] (h) Ball M, Baron A, Bradshaw B, Omori H, MacCormick S, Thomas EJ. Tetrahedron Lett 2004;45:8737. (i) Hale KJ, Frigerio M, Hummersone MG, Manaviazar S. Org. Lett 2003;5:503. [PubMed: 12583754] (j) Hale KJ, Frigerio M, Manaviazar S, Hummersone MG, Fillingham IJ, Barsukov IG, Damblon CF, Gescher A, Roberts GCK. Org. Lett 2003;5:499. [PubMed: 12583753]

(4)(a). Moslin RM, Jamison TF. J. Am. Chem. Soc 2006;128:15106. [PubMed: 17117859] (b) Kiyooka, S.-i.; Hena, MA. J. Org. Chem 1999;64:5511. [PubMed: 11674615] (c) Smith AB III, Chen SSY, Nelson FC, Reichert JM, Salvatore BA. J. Am. Chem. Soc 1997;119:10935. (d) Barchi JJ, Moore RE, Patterson GML. J. Am. Chem. Soc 1984;106:8193.

(5). Smith AB III, Razler TM, Meis RM, Pettit GR. Org. Lett 2006;8:797. [PubMed: 16468770]

(6)(a) . Machrouhi F, Hamann B, Namy J-L, Kagan HB. Synlett 1996:633. (b) Inanaga J, Ishikawa M, Yamaguchi M. Chem. Lett 1987:1485.

(7). For an isolated example of a related cyclization using an unfunctionalized saturated alkyl iodide, see: Kawamura K, Hinou H, Matsuo G, Nakata T. Tetrahedron Lett 2003;44:5259.

(8). Since the reaction could be driven by steady addition of portions of dibromoethane, we attribute the low yields to a combination of a lack of adequate reactivity of the allyl chloride and surface activation of the magnesium; the reaction scale was $0.36 \mathrm{mmol}$ of starting chloride.

(9)(a). Keck GE, Truong AP. Org. Lett 2005;7:2149. [PubMed: 15901156] (b) Keck GE, Truong AP. Org. Lett 2005;7:2153. [PubMed: 15901157] (c) Keck GE, Covel JA, Schiff T, Yu T. Org. Lett 2002;4:1189. [PubMed: 11922815]

(10). Neises B, Steglich W. Angew. Chem., Int. Ed. Engl 1978;17:522.

(11). Evans DA, Wu LD, Wiener JJM, Johnson JS, Ripin DHB, Tedrow JS. J. Org. Chem 1999;64:6411.

(12). Corey EJ, Venkateswarlu A. J. Am. Chem. Soc 1972;94:6190.

(13)(a). Inanaga J, Hirata K, Saeki H, Katsuki T, Yamaguchi M. Bull. Chem. Soc. Jpn 1979;72:1989. (b) Hikota M, Tone H, Horita K, Yonemitsu O. Tetrahedron 1990;46:4613.

(14). This macrolactonization procedure has been thoroughly optimized and care has also been taken to document the reproducibility of the yield for this reaction.

Org Lett. Author manuscript; available in PMC 2008 August 14. 
<smiles>[R2][C@H]1CCCC(=O)O1</smiles><smiles>[R]N1CCCC1</smiles><smiles>[R7][C@H]1CCCC([R2])(O)O1</smiles><smiles>[R]C(O)CCC[C@@H]([R2])O</smiles>

$\underset{\text { 1) Oxidation }}{\stackrel{\text { Deprotection }}{\longrightarrow}}$<smiles>[R7][C@H]1CCCC([R2])(O)O1</smiles>

Scheme 1.

Typical Lactol Syntheses 


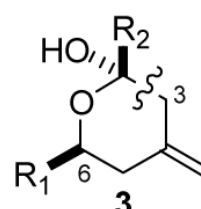<smiles>[R][R]1OC(=O)OC([R])C1=C</smiles><smiles>[X]CC(=C)C([R])C([R])[O-]</smiles>

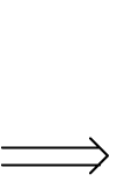

O 6

$1-R_{2}$<smiles>[R]C(O)CC(=C)CCl</smiles>

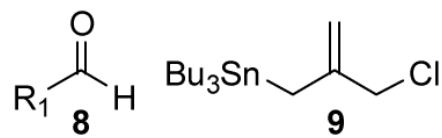

Scheme 2.

Retrosynthetic Approach 


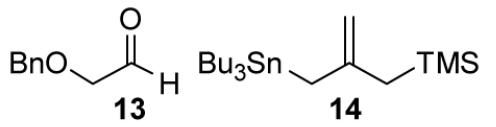

1) R-BITIP;

$88 \%, 95: 5$ er

2) TMSOTf, $97 \%$

$\prod_{\mathrm{O}}^{15} 15$

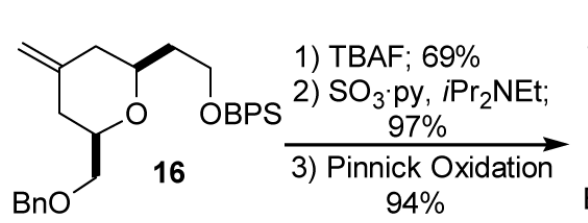

1) TBAF; $69 \%$

2) $\mathrm{SO}_{3} \cdot \mathrm{py}, \mathrm{Pr}_{2} \mathrm{NEt}$;

$94 \%$<smiles>C=C(CCl)C[SbH2]CCCCCCC(=O)OCCCC</smiles>

S-BITIP: 83\%, 99:1 er

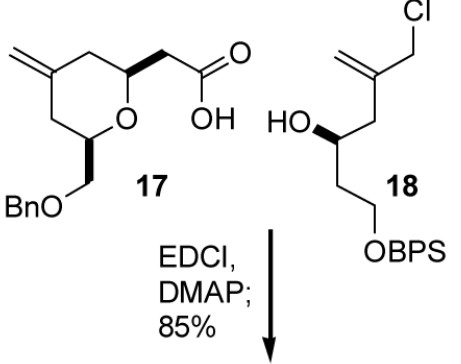<smiles>C=C(CCl)C[C@H](CC[R5]#[SH])OC(=O)C[C@H]1CC(=C)C[C@H](COc2ccccc2)O1</smiles>

Scheme 3.

Synthesis of Simplified Bryostatin AB Ring System 


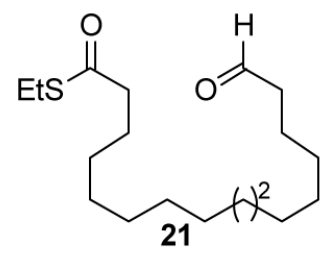

1) $S-B I T I P$,<smiles>CCCCCCCCCCC</smiles><smiles>C=C(C)CCl</smiles><smiles>C=C(CCl)C[C@H](CCCCCCCCCCCCC(=O)SCC)OS(=O)(=O)CCCCC</smiles>

1) $\mathrm{LiOH}, \mathrm{H}_{2} \mathrm{O}_{2}$ $96 \%$

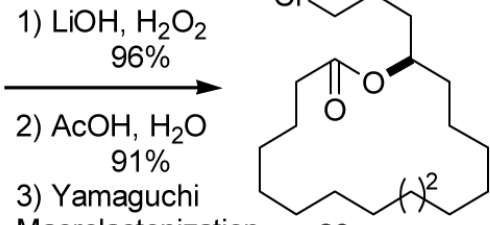
Macrolactonization 23 $92 \%$

Scheme 4.

Synthesis of a Macrocyclic 2-Methoxypyran

1) $\mathrm{Nal}$, acetone $97 \%$

2) $\mathrm{Sml}_{2}, \mathrm{THF}, \mathrm{O}^{\circ} \mathrm{C}$ 3) $\mathrm{MeOH}, \mathrm{CH}_{2} \mathrm{Cl}_{2}$ CSA $88 \%$ (2 steps)

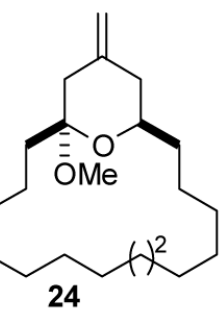




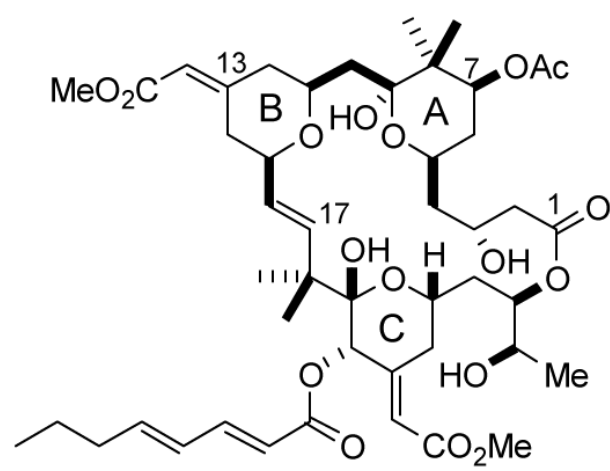

1 Bryostatin 1

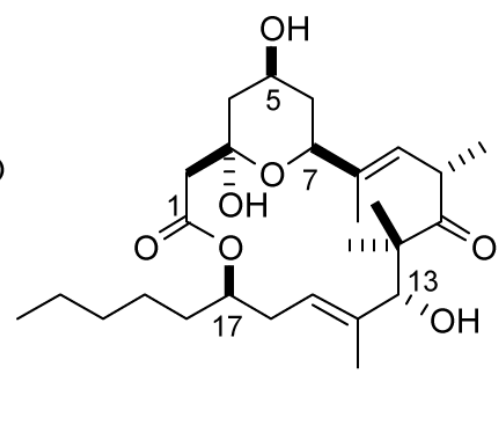

2 Acutiphycin

Figure 1.

Structures of Bryostatin and Acutiphycin 
Conditions for Reductive Cyclizations

Table 1

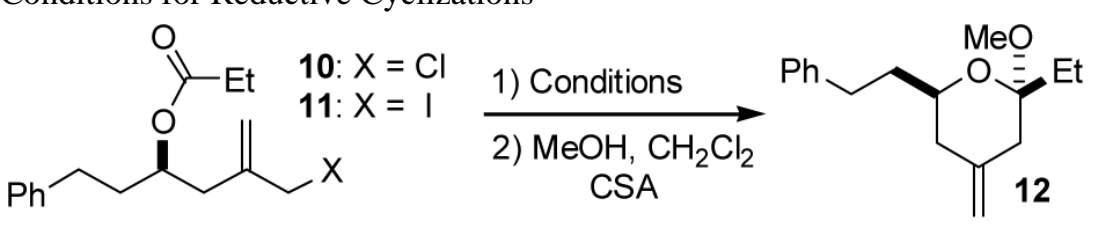

\begin{tabular}{|c|c|c|c|c|}
\hline $\operatorname{compound}^{(a)}$ & reductant & solvent & temperature & yield $^{(b)}$ \\
\hline 10 & $\mathrm{Mg}$ & $\mathrm{Et}_{2} \mathrm{O}$ & $\mathrm{rt}$ & $11 \%$ \\
\hline 10 & $\mathrm{Mg}$ & THF & rt to reflux & NR \\
\hline 10 & $\mathrm{SmI}_{2}$ & THF & $\mathrm{rt}$ & NR \\
\hline 10 & $\mathrm{SmI}_{2} /$ cat.NiI 2 & THF & $\mathrm{rt}$ & NR \\
\hline 10 & $\mathrm{SmI}_{2} /$ cat. $\mathrm{NiI}_{2}$ & THF/HMPA & $\mathrm{rt}$ & NR \\
\hline 11 & $\mathrm{Mg}$ & $\mathrm{Et}_{2} \mathrm{O}$ & $\mathrm{rt}$ & $54 \%$ \\
\hline 11 & In & THF & $\mathrm{rt}$ & complex mixture \\
\hline 11 & $t$-BuLi & THF & $-78^{\circ} \mathrm{C}$ & $33 \%$ \\
\hline 11 & $\mathrm{SmI}_{2}$ & THF & $0^{\circ} \mathrm{C}$ & quant \\
\hline
\end{tabular}

${ }^{(a)}$ In some cases the racemic ester was used.

(b) In some cases a mixture of the two anomers was obtained. 


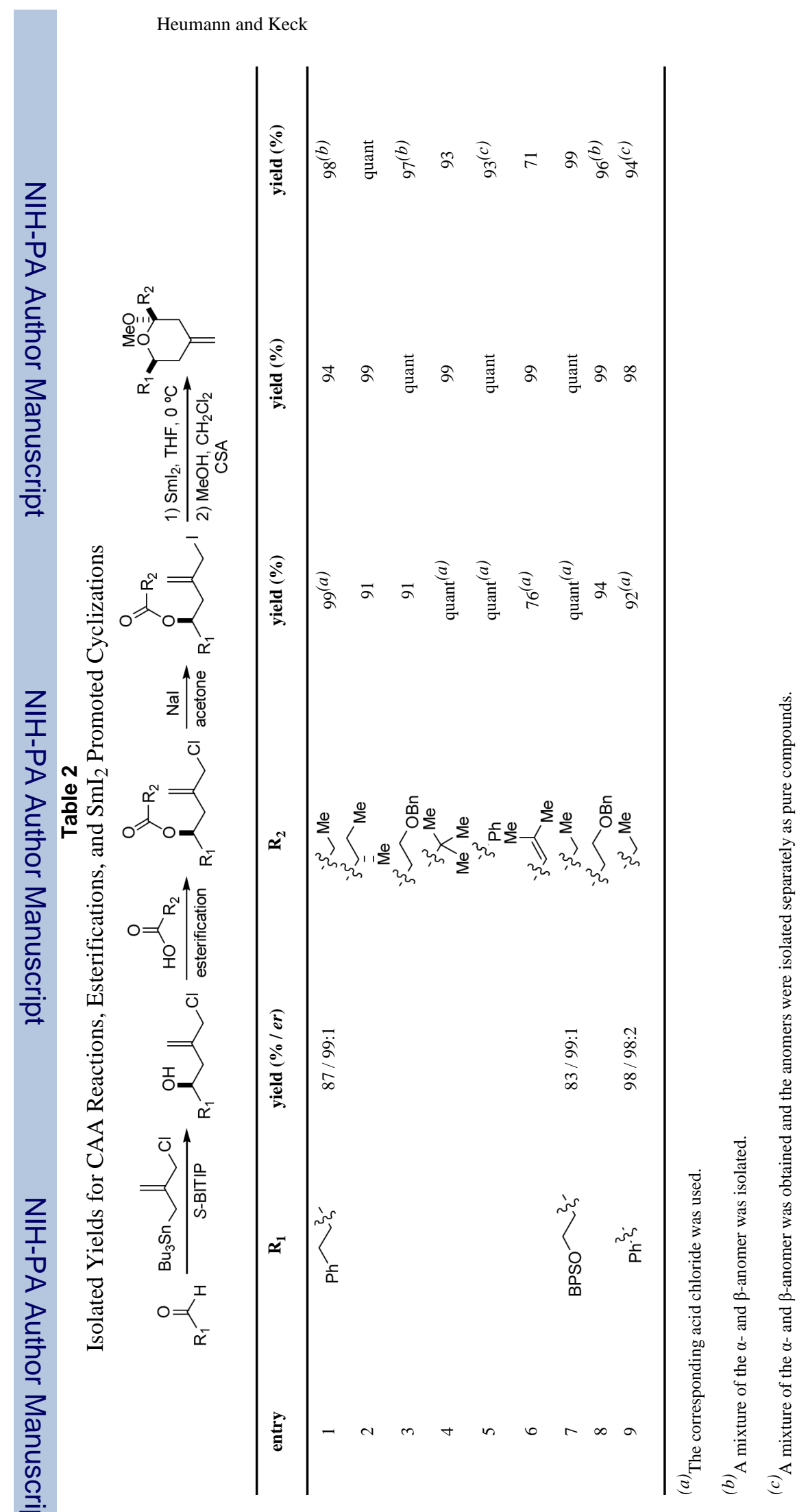

Org Lett. Author manuscript; available in PMC 2008 August 14. 